\title{
Costly Renegotiation in Repeated Bertrand Games*
}

\author{
Ola Andersson ${ }^{\dagger}$ and Erik Wengström ${ }^{\ddagger}$ \\ SSE/EFI Working Paper Series in Economics and Finance, No 725
}

March 23, 2010

\begin{abstract}
This paper extends the concept of weak renegotiation-proof equilibrium (WRP) to allow for costly renegotiation and shows that even small renegotiation costs can have dramatic effects on the set of equilibria. More specifically, the paper analyzes the infinitely repeated Bertrand game. It is shown that for every level of renegotiation cost there exists a discount factor such that any collusive profit can be supported as an equilibrium outcome. Hence, any arbitrary small renegotiation cost will suffice to facilitate collusive outcomes for sufficiently patient firms. This result stands in stark contrast to the unique pure-strategy WRP equilibrium without renegotiation costs, which implies marginal-cost pricing in every period. Moreover, in comparison to the findings of McCutcheon (1997), who states that renegotiation costs have to be substantial to facilitate collusion, this result points to a quite different conclusion.

Keywords. Noncooperative game theory; Weak renegotiationproofness; Costly renegotation; Repeated Bertrand games

JEL-codes. C72; D43
\end{abstract}

\section{Introduction}

It is well known that in infinitely repeated games, every feasible and individually rational payoff vector can be implemented as a subgame perfect equilibrium

\footnotetext{
${ }^{*}$ We are grateful to Andreas Blume, Hans Carlsson, Joseph Farrell, Sebastian Kranz and participants at the Centre for Industrial Economics Christmas Workshop in Copenhagen for helpful comments. Financial support from the Wallander-Hedelius foundation is gratefully acknowledged.

${ }^{\dagger}$ Department of Economics, Stockholm School of Economics, Sveavägen 65, SE-113 83 Stockholm Sweden.

${ }^{\ddagger}$ Department of Economics, Lund University, PO Box 7082, SE-222 07 Lund, Sweden and Department of Economics, University of Copenhagen, Øster Farimagsgade 5, bygning 261353 København, Denmark
} 
(SPE) for sufficiently high discount factors. This inconclusive result has spurred a large literature on equilibrium selection, and in this vein Farrell and Maskin's (1989) concept of weak renegotiation-proof equilibrium (WRP) has received considerable attention. In short, WRP considers threats of punishment noncredible if they hurt all players; the argument being that players would then prefer to renegotiate back to a collusive outcome rather than staying in the costly punishment phase, which undermines the credibility of the threat. WRP and related constructs assume that renegotiation can be initiated without inflicting any costs on the renegotiating parties 11 However, in many applications, renegotiation is associated with a cost. For example, firms trying to renegotiate a collusive agreement after a deviation face the risk of leaving evidence of communication that may be used against them in future allegations. Seen in this light, renegotiation can hardly be considered as costless. Analyzing the effects of costly renegotiation is hence central to understanding the role of renegotiation in many settings and constitutes the purpose of this paper.

More specifically, the paper makes a twofold contribution. Firstly, we present a simple extension of WRP to account for renegotiation costs. To our knowledge this is the first attempt to allow for renegotiation costs in a WRP context, and even though our definition is given for a specific game, it is easily extended to other settings. Secondly, we analyze the implications of costly renegotiation in the infinitely repeated Bertrand duopoly game. The Bertrand case is interesting as it has a unique WRP in pure strategies that implies marginal cost pricing in every period (Farrell and Maskin 1989) ${ }^{2}{ }^{3}$ We provide a lower bound on renegotiation costs, as a function of discount factors, that makes collusion viable, and show that: (i) for every positive level of renegotiation cost there exists a discount factor such that collusion is viable, (ii) as the discount factor gets close to one, any arbitrarily small renegotiation cost will suffice to facilitate collusion. This folk-theorem result stands in stark contrast to both Farrell and Maskin's (1989) competitive outcome prediction in situations without renegotiation costs, and McCutcheon (1997) who argues that costs have to be larger than the stage game collusive profit to support collusion.

The latter point in the previous paragraph deserves some elaboration to be appreciated. McCutcheon (1997) is set in an antitrust setting where the fines from being detected by the antitrust authority are treated as a cost of (re)negotiation ${ }^{4}$ Her main contribution is that she provides a lower bound on renegotiation costs such that if costs are larger than this threshold, collusion is

\footnotetext{
${ }^{1}$ See for example Bernheim, Peleg, and Whinston (1987), Bernheim and Ray (1987) and Asheim (1991) for related concepts which all assume costless renegotiation.

${ }^{2}$ In many other applications unfortunately WRP has not been successful in significantly reducing the number of attainable equilibrium outcomes. van Damme (1989) shows that WRP does not eliminate any subgame perfect equilibrium outcome in prisoners' dilemma games. A similar result is shown to hold for Cournot duopolies (Farrell and Maskin 1989) and a subsequent paper has shown that this result continues to hold for Cournot oligopolies with fewer than 9 firms (Aramendia and Ruiz 2005).

${ }^{3}$ In a recent paper Kranz and Ohlendorf (2009) have shown that introducing side payments changes this result.

${ }^{4}$ This presumes that explicit meetings are necessary to achieve collusion among firms. Theory is often silent on these matters, but relies on the underlying assumption of perfect
} 
possible and otherwise not. In particular, she shows that fines have to be substantial to facilitate collusion; when firms are very patient, renegotiation costs have to be above the stage game collusive profit to facilitate collusion. The immediate implication for policy is that antitrust laws prohibiting communication between firms facilitate, rather than impede, collusion. This controversial result has rendered numerous citations, but more importantly it has been used in applied policy work (Final Report for the European Commission 2001) as well as in economics textbooks (Motta 2004). This result obviously conflicts with our finding that any positive renegotiation cost will enable collusion for sufficiently patient firms. We argue that McCutcheon's result is an artifact of a questionable modeling choice. She uses Farrell and Maskin (1989) to predict a competitive outcome in a situation without fines. WRP relies on using asymmetric punishments that treat the cheater worse than the cheated. However, McCutcheon (1997) restricts attention to strategies with symmetric punishments when she applies Blume (1994) to the case of costly renegotiation $5^{5}$ This clearly creates an inconsistency, which, as we show, has dramatic effects.

Further support to our results is given in a recent experimental paper on collusion in repeated Bertrand duopolies with (costly) communication (Andersson and Wengström 2007a). They conduct three treatments with zero, low or high cost of communication. In particular, the high cost communication treatment is set up so that the cost is high enough to support collusion both according to our lower bound, given in Proposition 1, and the lower bound given in McCutcheon. In contrast, the low communication cost treatment is too low to support collusion according to McCutcheon, but sufficiently high according to our lower bound. Andersson and Wengström (2007a) report that prices in sessions with costly communication are higher than in sessions with costless communication, whereas there is no difference between prices in sessions with costly communication; thus giving support to the theory put forward in this paper.

\section{Theoretical model}

We consider an infinitely repeated Bertrand duopoly where each firm $i=1,2$ chooses a price $p_{i} \in P_{i}=\mathbb{R}_{+}$in each period $\left.t \in\{1, \ldots, \infty\}=\mathbb{T}\right]^{6}$ Assume that firms have an identical constant marginal cost $c$ and denote the stage game

and frictionless negotiations that occur in the minds of firms. A discussion of what is more plausible in "reality" would take us far outside the realms of this paper and instead we refer to Farrell (2000) for a discussion on these matters and Genesove and Mullin (2001) for empirical evidence of explicit communication between colluding firms.

${ }^{5}$ Note that we do not argue against Blume's approach per se. We question how McCutcheon (1997) uses it in her article.

6 The results in this paper are easily extended to games with more than two players. In line with the concluding remarks in Farrell and Maskin (1989) we, however, argue that WRP is best suited to describe two player games, since for more players there could be renegotiation by sub-coalitions, which is not captured. 
profit: $\pi_{i}\left(p_{i}, p_{j}\right)=\left(p_{i}-c\right) D_{i}\left(p_{i}, p_{j}\right)$. Firm $i$ 's demand, $D_{i}$ is given by:

$$
D_{i}\left(p_{i}, p_{j}\right)= \begin{cases}D\left(p_{i}\right) & \text { if } p_{i}<p_{j} \\ \frac{1}{2} D\left(p_{i}\right) & \text { if } p_{i}=p_{j} \\ 0 & \text { if } p_{i}>p_{j}\end{cases}
$$

where $D\left(p_{i}\right)$ denotes aggregate demand which is assumed to be continuous and decreasing. Furthermore, let $D(0)>c$ and $D\left(p_{i}\right)=0$ for $p_{i} \geq p^{\max }>0$. These assumptions preclude some trivial cases and guarantee that there exists a monopoly price $p^{m}$. It is easily realized that the unique pure strategy Nash equilibrium of the stage game is both firms setting price equal to marginal cost. After each stage, firms learn the price choice of the other firm. Let $\sigma=\left(\sigma_{1}, \sigma_{2}\right)$ denote a strategy profile ${ }^{78} \mathrm{We}$ denote firm $i$ 's present value of profits $\Pi_{i}(\sigma)=\sum_{t=1}^{\infty} \delta^{t-1} \pi_{i}\left(\sigma_{t}\right)$, where $\delta \in(0,1)$ is the common discount factor. Moreover, let $\Pi(\sigma)=\left(\Pi_{1}(\sigma), \Pi_{2}(\sigma)\right)$. Before each stage of the game, firms have the opportunity to renegotiate at cost $k>09^{9}$ This cost is inflicted on both firms in case of renegotiation. Let $\boldsymbol{k}$ denote the vector of renegotiation costs. We now give a definition of costly WRP which is closely related to the definition of WRP in Farrell and Maskin (1989).

Definition 1 A subgame perfect equilibrium $\sigma$ is $k$-WRP if there does not exist any continuation equilibria $\sigma^{1}$ or $\sigma^{2}$ of $\sigma$ such that $\Pi\left(\sigma^{1}\right)-\boldsymbol{k} \geq \Pi\left(\sigma^{2}\right)$ with strict inequality for at least one element. If $\sigma k$-WRP then we say that the corresponding profits are $k$-WRP.

\section{Analysis}

We are interested in characterizing the conditions needed to sustain collusive outcomes as k-WRP equilibria. A first condition for a strategy to be k-WRP is that it is a subgame perfect equilibrium, hence we first need to establish conditions on $\delta$ for the existence of non-trivial SPE, in which price is not equal to marginal cost in every period. From textbook treatments of Bertrand duopolies we know that this lower bound is given by $\delta \geq \frac{1}{2}{ }^{10}$ Consequently we restrict attention to $\delta \in\left[\frac{1}{2}, 1\right)$. In what follows we assume that firms use the following strategy, with corresponding profile $\bar{\sigma}$.

\footnotetext{
${ }^{7}$ As usual $\sigma_{i}$ is an infinite sequence of maps from the set of histories to the set of stage game actions.

${ }^{8}$ In line with McCutcheon (1997) we restrict attention to pure strategies.

${ }^{9}$ We assume that an initial agreement has already been set up by the colluding firms and that this initial agreement is not associated with any cost. The model is easily extended, without affecting the results, to allow for costly initial agreements as it does not alter the lower bound on renegotiation cost. Instead it introduces an upper bound on (re)negotiation cost such that above this bound firms do not meet to set up the initial agreement. Note that in order for this restraint to be binding the cost has to exceed the present value of all individual future profit streams from the cartel. Also note that this upper bound would be identical to the upper bound derived in McCutcheon (1997).

${ }^{10}$ See for example Tirole (1988).
} 
- Normal state: Both firms set $p=\bar{p} \in\left(c, p^{m}\right]$ at $t=1$ and at every $t>1$ if for both firms $p=\bar{p}$ in the previous period or if firms were in the last stage of a punishment phase in the previous period 11 Otherwise, firms revert to the punishment state.

- Punishment state: If firm $i$ deviates at $t$ then firms revert to choosing $p_{j}^{i}$ and $p_{i}^{i}$ for $T$ periods such that $p_{j}^{i}<p_{i}^{i}$. Let $\pi^{i}=\left(\pi_{i}^{i}, \pi_{j}^{i}\right)$ be the corresponding stage game profits. If firm $i$ deviates from the punishment, it restarts. If firm $j$ deviates, it is required to punish itself for $T$ periods and firm $i$ is reprieved. If both firms deviate then firm 2 is punished. After $T$ periods firms return to the normal state.

Letting $\bar{\pi}$ denote the monopoly profit from setting price $\bar{p}$, we can characterize the lowest renegotiation cost needed to sustain collusive pricing in equilibrium.

To establish whether a strategy profile $\bar{\sigma}$ is $\mathrm{k}$-WRP we must check that there is no collective interest in renegotiating a punishment and paying the cost $k$. Now assume that firm $i$ has deviated. Since firm $i$ is then being punished, it prefers renegotiating and it hence suffices to check this requirement for firm $j$. Firm $j$ should strictly prefer staying in the punishment to renegotiating and paying $k$. This incentive is strongest in the first period of the punishment. A sufficient condition is

$$
\frac{1-\delta^{T}}{1-\delta} \cdot \pi_{j}^{i}>\frac{1-\delta^{T}}{1-\delta} \cdot \frac{\bar{\pi}}{2}-k
$$

Which simplifies to

$$
\pi_{j}^{i}>\frac{\bar{\pi}}{2}-k \cdot \frac{1-\delta}{1-\delta^{T}} .
$$

Clearly, if $\pi_{j}^{i}$ meets inequality (1) there is no collective interest in renegotiating the punishment since the cheated firm is strictly better off sticking to the punishment phase.

We also need to check that the strategy profile is an SPE. First, we need to make sure that no firm has an incentive to deviate from the normal path. That is, firm $i$ punishes itself for $T$ periods such that the following holds

$$
\frac{\bar{\pi}}{2} \cdot \frac{1}{1-\delta} \geq \bar{\pi}+\frac{\bar{\pi}}{2} \cdot \frac{\delta^{T+1}}{1-\delta} .
$$

To find the lower bound on renegotiation costs, the length of the punishment phase should be minimized; we therefore define $T(\delta)$ to be the smallest positive integer satisfying (2), i.e

$$
T(\delta) \equiv \min \left\{t \in \mathbb{T} \mid t \geq \frac{\ln (-1+2 \delta)}{\ln (\delta)}-1\right\} .
$$

\footnotetext{
${ }^{11}$ The restiction $\bar{p} \leq p^{m}$ is without loss of generality.
} 
A second criterion to ensure that $\bar{\sigma}$ is SPE is that the punished firm should have no interest in deviating from the punishment path by undercutting firm $j$, i.e. the following must hold

$$
\frac{\bar{\pi}}{2} \cdot \frac{\delta^{T(\delta)}}{1-\delta} \geq \pi_{j}^{i}+\frac{\bar{\pi}}{2} \cdot \frac{\delta^{T(\delta)+1}}{1-\delta} .
$$

Or equivalently,

$$
\delta^{T(\delta)} \frac{\bar{\pi}}{2} \geq \pi_{j}^{i}
$$

By comparing inequalities (1) and (4) we see the force of the renegotiation cost $k$. In essence it introduces a wedge between $\pi_{j}^{i}$ and the collusive profit $\bar{\pi} / 2$ in (1), which can subsequently be used to avoid deviations from the punishment path in (4).

Replacing $\pi_{j}^{i}$ in equation 4 with inequality (1) we get

$$
k>\frac{\bar{\pi}}{2} \cdot \frac{\left(1-\delta^{T(\delta)}\right)^{2}}{1-\delta} \equiv \underline{k}(\delta)
$$

which sets a lower bound on the renegotiation cost. We can summarize our results in the following Proposition:

Proposition 1 If $k>\underline{k}(\delta)$ then $\bar{\sigma}$ is $k$-WRP.

We notice that if a particular profit is $\mathrm{k}$-WRP then any collusive profit is $\mathrm{k}$-WRP, which is a common property in the repeated Bertrand game. An interesting question is whether we, for every $k>0$, can find discount factors such that collusion is viable. From the previous paragraph it is clear that for large $k$, collusion can be easily sustained since it effectively prevents any profitable renegotiation attempt and still provides room for repentance to the cheated firm. For small $k$ it is not so obvious. The model in McCutcheon (1997) provides a negative answer to this question. In contrast, Theorem 1 shows that this is indeed the case in our model.

Theorem 1 For any $k>0$ there exists $\delta \in(0,1)$ such that $\bar{\sigma}$ is $k$-WRP.

A proof of Theorem 1 can be found in the Appendix. By the definition of $\bar{\sigma}$ it is clear that any positive stage game profit can be implemented as a $\mathrm{k}$-WRP profit for sufficiently large $\delta$. An immediate corollary to Theorem 1 is that even an infinitely small renegotiation cost can support collusive equilibria, given that firms are patient enough 12 In Figure 1 we have plotted $\underline{k}(\delta)$ for $\delta \in(0.5,1)$. The jumps for low $\delta$ are due to the changes in the minimal punishment length $T(\delta)$. However, by studying equation (3) we see that $T(\delta)=2$ for all $\delta \geq$ $-1 / 2+1 / 2 \sqrt{5} \approx 0.62$. For $\delta$ above this threshold it can be easily shown that

\footnotetext{
${ }^{12}$ However, Farrell and Maskin (1989) have shown that, for $k=0$ and $\delta$ sufficiently close to one, the unique WRP equilibrium entails marginal cost pricing in every period. This lack of continuity at the limit might seem troublesome but Andersson and Wengström (2007b) have shown that Farrell and Maskin's result is sensitive to discontinuities in the strategy space.
} 


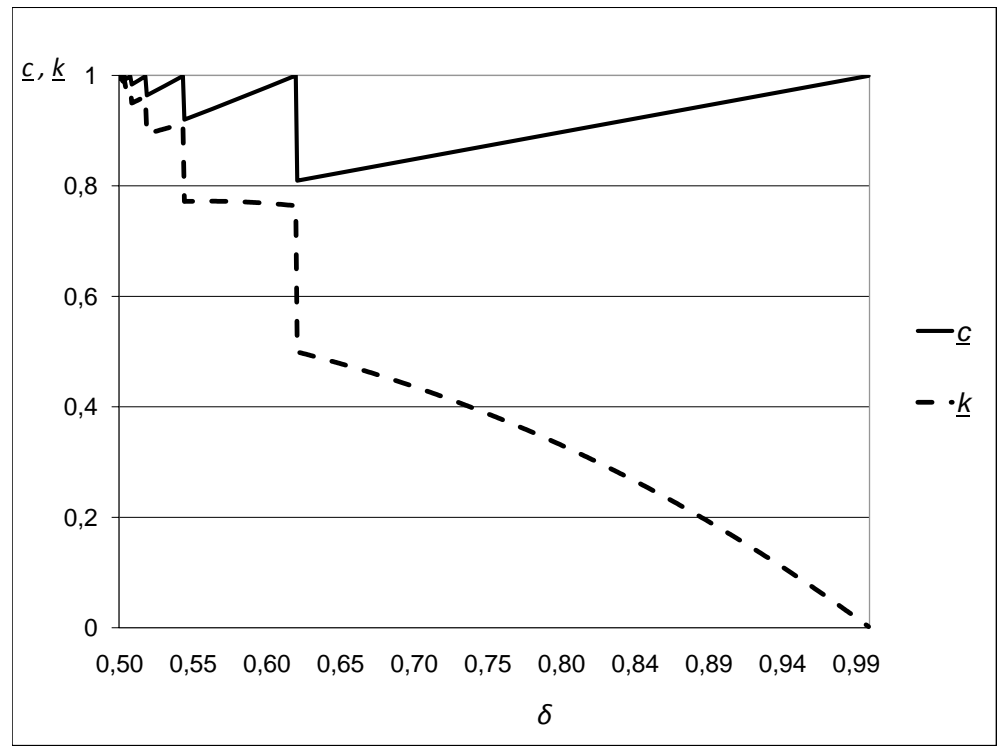

Figure 1: An example with $\bar{\pi}=1$

$\underline{k}(\delta)$ is strictly decreasing in $\delta$, hence implying that if, for fixed $k$, collusion is viable at some particular $\bar{\delta} \geq 0.62$, then collusion is viable for all $\delta \geq \bar{\delta}$. Indeed, the reader can verify that that the result in Theorem 1 is not merely a "limit" result.

Finally we compare our results to those in McCutcheon (1997). First, note that she uses the same punishment length as we do when deriving her lower bound on renegotiation costs. It is hence straightforward to compare our lower bound $\underline{k}(\delta)$ to her lower bound given by

$$
\frac{\bar{\pi}}{2} \frac{\left(1-\delta^{T}\right)}{1-\delta} \equiv \underline{c}(\delta)
$$

Comparing the two lower bounds in Figure 1 it is clear that $\underline{c}(\delta)>\underline{k}(\delta)$ in the relevant range of $\delta$. In particular, for any $\bar{\pi}$, as $\delta \rightarrow 1^{-}$the lower bound $\underline{k}(\delta)$ converges to zero while $\underline{c}(\delta)$ converges to $\bar{\pi}$. Clearly, she cannot derive an equivalent to Theorem 1 using her setup.

\section{Concluding remarks}

In this paper we show that any strictly positive renegotiation cost will suffice to enable collusion according to our definition. More generally, this result conforms to the folk theorem and, hence, renegotiation opportunities cannot be seen as a serious impediment to collusion in Bertrand games. Drawing a parallel to 
the policy conclusions in McCutcheon (1997), our Proposition11 highlights that making renegotiation cheap does not prevent firms from sustaining collusive agreements. Indeed, given that it is very likely that some costs will always be associated with collusive agreements, irrespective of antitrust fines, it is hard to support her conclusion that these fines should be kept low. To the contrary, the only alternative left to consider is to rule out the initial agreement and hence expected antitrust fines should be larger than the discounted stream of future collusive profits. A potential objection to our argument is that the limit result is a special case. However, McCutcheon (1997) obtains a discount factor of $\delta=0.99969$, a number fairly close to one, when she calibrates her model using historical data. Accordingly, we argue that the limiting case is indeed relevant for policy application. In addition, the experimental results in Andersson and Wengström (2007a) favor our model over McCutcheon (1997).

\section{Appendix}

\subsection{Proof of Theorem 1}

In what follows, we will establish that, for any $k>0$, there exists some $\delta \in$ $(0.5,1)$ such that $\bar{\sigma}$ is $\mathrm{k}$-WRP. More precisely, we proceed by fixing $k>0$ and study $\underline{k}$ as $\delta$ increases towards one. It is important to pay attention since $T(\delta)$ depends on $\delta$.

The RHS of the inequality in (3) is strictly greater than one for $\delta<1$, hence $\lim _{\delta \rightarrow 1^{-}} T(\delta)=2$. Using L'Hôpital's rule to evaluate the RHS of inequality (3) we get

$$
\lim _{\delta \rightarrow 1^{-}}\left(\frac{\ln (-1+2 \delta)}{\ln (\delta)}-1\right)=\lim _{\delta \rightarrow 1^{-}}\left(\frac{2 \delta}{2 \delta-1}-1\right)=1 .
$$

In fact, a numerical calculation shows that $T(\delta)=2$ for $\delta \in\left(-1 / 2 \frac{\sqrt{(5)}}{2}, 1\right) \sqrt{13} \mathrm{We}$ fix a finite $T>0$ and turn attention to finding the lower bound of communication costs, $\underline{k}$, needed to sustain $\bar{\sigma}$ as k-WRP. By applying L'Hôpital's rule to the expression of $\underline{k}$ given in Proposition 1 , we see that

$$
\lim _{\delta \rightarrow 1^{-}}\left(\frac{\bar{\pi}}{2} \cdot \frac{\left(1-\delta^{T}\right)^{2}}{1-\delta}\right)=\lim _{\delta \rightarrow 1^{-}} 2\left(\cdot\left(1-\delta^{T}\right) \cdot T \cdot \delta^{T-1}\right)=0 .
$$

Given, $k>0$ there clearly exists $\delta<1$ such that $k>\underline{k}$. Using Proposition 1 the result follows.

\section{References}

(2001): "Final Report for the European Commission Enterprise Directorate General (2001) Study on Assessment Criteria for Distinguishing between Competitive and Dominant Oligopolies in Merger Control," .

\footnotetext{
$13-1 / 2+1 / 2 \sqrt{5}$ is approximately equal to 0.62 .
} 
Andersson, O., And E. Wengström (2007a): "Do Antitrust Laws Facilitate Collusion? Experimental Evidence of Costly Communication in Duopolies," Scandinavian Journal of Economics, 109, 321-339.

- (2007b): "A Note on Renegotiation in Repeated Bertrand Duopolies," Economics Letters, 95, 398-401.

Aramendia, M., And C. L. Ruiz (2005): "Renegotiation in the repeated Cournot model," Games and Economic Behavior, 52, 1-19.

Asheim, G. B. (1991): "Extending renegotiation-proofness to infinite horizon games," Games and Economic Behavior, 3(3), 278-294.

Bernheim, D., B. Peleg, and M. Whinston (1987): "Coalition-Proof Nash Equilibria I. Concepts," Journal of Economic Theory, 42, 1-12.

Bernheim, D., AND D. RAY (1987): "Collective dynamic consistency in repeated games," Games and Economic Behavior, 1, 295-326.

Blume, A. (1994): "Intraplay Comunication in Repeated Games," Games and Economic Behavior, 6, 181-211.

FARRELL, J. (2000): Renegotiation in repeated oligopoly interaction pp. 303-322, In: G. Myles and P. Hammond, Editors Incentives, Organization, and Public Economics: Papers in Honour of Sir James Mirrlees. Oxford Univ. Press.

FARrell, J., AND E. MASKIN (1989): "Renegotiation in Repeated Games," Games and Economic Behavior, 1, 327-360.

Genesove, D., And W. Mullin (2001): "Rules, Communication and Collusion: Narrative Evidence from the Sugar Institute Case," The American Economic Review, 91, 379-398.

Kranz, S., And S. Ohlendorf (2009): "Renegotiation-Proof Relational Contracts with Side Payments," Discussion Papers 259, SFB/TR 15 Governance and the Efficiency of Economic Systems, Free University of Berlin, Humboldt University of Berlin, University of Bonn, University of Mannheim, University of Munich.

McCutcheon, B. (1997): "Do Meetings in Smoke-Filled Rooms Facilitate Collusion?," Journal of Political Economy, 105(2), 300-350.

Motta, M. (2004): Competition Policy Theory and Practice. Cambridge University Press, Cambridge, United Kingdom.

Tirole, J. (1988): The Theory of Industrial Economics. MIT Press, Cambridge, Massachusetts.

VAN DAmme, E. (1989): "Renegotiation-proof Equilibria in Repeated Prisoners' Dilemma," Journal of Economic Theory, 47, 206-217. 